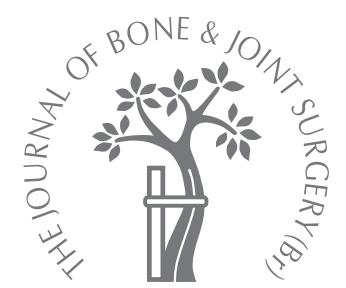

\title{
High incidence of loosening of the femoral component in legacy posterior stabilised-flex total knee replacement
}

\begin{abstract}
H. S. Han, S.-B. Kang, K. S. Yoon
\end{abstract}

From Seoul National University College of Medicine, Seoul, Korea

H. S. Han, MD, Clinical Professor

- S.-B. Kang, MD, PhD, Associate Professor

K. S. Yoon, MD, PhD Associate Professor Department of Orthopaedic Surgery

Seoul National University College of Medicine, Seoul Metropolitan Boramae Hospital, 31-1 Boramae-gil, Dongjak-gu, 156-707 Seoul, Korea.

Correspondence should be sent to Professor S.-B. Kang; e-mail: ossbkang@gmail.com

(C2007 British Editorial Society of Bone and Joint Surgery doi:10.1302/0301-620X.89B11. $19840 \$ 2.00$

$J$ Bone Joint Surg [Br] 2007;89-B:1457-61. Received 20 June 2006 ; Accepted 3 August 2007

We have examined the results obtained with 72 NexGen legacy posterior stabilised-flex fixed total knee replacements in 47 patients implanted by a single surgeon between March 2003 and September 2004.

Aseptic loosening of the femoral component was found in $27(38 \%)$ of the replacements at a mean follow-up of 32 months ( 30 to 48 ) and 15 knees $(21 \%)$ required revision at a mean of 23 months (11 to 45). We compared the radiologically-loose and revised knees with those which had remained well-fixed to identify the factors which had contributed to this high rate of aseptic loosening.

Post-operatively, the mean maximum flexion was $136^{\circ}\left(110^{\circ}\right.$ to $\left.140^{\circ}\right)$ in the loosened group and $125^{\circ}\left(95^{\circ}\right.$ to $\left.140^{\circ}\right)$ in the well-fixed group (independent $t$-test, $p=0.022$ ).

Squatting, kneeling, or sitting cross-legged could be achieved by $23(85 \%)$ of the loosened knees, but only $22(49 \%)$ of the well-fixed knees (chi-squared test, $p=0.001)$. The loosened femoral components were found to migrate into a more flexed position, but no migration was detected in the well-fixed group.

These implants allowed a high degree of flexion, but showed a marked rate of early loosening of the femoral component, which was associated with weight-bearing in maximum flexion.

The impressive long-term outcome and excellent survivorship of total knee replacement (TKR) have been well described. ${ }^{1-3}$ However, limitation in flexion which prevents the restoration of full pre-operative activities remains a problem. Most available designs of TKR achieve flexion of $110^{\circ}$ to $120^{\circ}$ compared with that of $150^{\circ}$ to $160^{\circ}$ in the normal knee. ${ }^{4,5}$ Squatting requires $130^{\circ}$ of flexion of the hip and $111^{\circ}$ to $165^{\circ}$ of the knee, and sitting cross-legged $90^{\circ}$ to $100^{\circ}$ of hip flexion and $111^{\circ}$ to $165^{\circ}$ knee flexion. ${ }^{6}$ Thus, although acceptable for many patients, TKR still restricts post-operative activities requiring high degrees of flexion such as squatting or kneeling. ${ }^{7}$

Numerous factors influence the maximum range of flexion after TKR, including the preoperative range of movement, body habitus, surgical technique, prosthetic design and postoperative rehabilitation. ${ }^{5,8}$ Several recent designs of implant have incorporated modifications to the geometry of the design intended to improve the post-operative range of movement. ${ }^{9}$ Some were introduced to create prostheses which were more durable and stable. They provided safe and adequate flexion by preventing loading on the edge of the posterior tibial articular surface and by increasing the tibiofemoral contact area at high flexion. ${ }^{10}$ The NexGen legacy posterior stabilised (LPS)-flex fixed TKR (Zimmer, Warsaw, Indiana) is designed to allow $155^{\circ}$ of knee flexion safely. In order to eliminate loading of the femoral component on the margin of the posterior tibial articular surface, the posterior femoral condyles must be extended, and to reduce impingement of the extensor mechanism in deep flexion, the anterior margin of the tibial articular component should be recessed. Additionally, a modified posterior stabilised cam/spine mechanism is required to increase resistance to subluxation at high angles of flexion.

However, concern has been expressed that the increased flexion which has enabled patients to squat or kneel successfully in the short term may compromise the long-term result. ${ }^{11}$ Removal of more bone from the posterior femoral condyles and the intercondylar area may expose weaker bone, which is less able to support the load transferred from the femoral component. There is also concern about instability in deep flexion. ${ }^{12}$ 
Loosening of the femoral component is a relatively infrequent complication of TKR and prior to the present study, the authors had never experienced a rate of early loosening of more than $5 \%$ for any other design.

We have analysed 72 TKRs of a high flexion design for evidence of aseptic loosening and related pain. We have reviewed the clinical history, radiological features and any findings at revision for factors which may have contributed to aseptic loosening.

\section{Patients and Methods}

Between March 2003 and September 2004, 72 consecutive TKRs were performed in 47 osteoarthritic patients by a single surgeon (SBK) using the NexGen LPS-flex (Zimmer), highflexion fixed TKR. All the components were cemented with Simplex P (Howmedica, Rutherford, New Jersey) bone cement. All the patellae were resurfaced with an allpolyethylene dome-shaped component, implanted with bone cement.

There were 44 women and three men with a mean age of 68.3 years ( 45 to 79 ) and a mean body mass index (BMI) of $26.1 \mathrm{~kg} / \mathrm{m}^{2}$ (19.4 to 32.0$)$.

Patients were treated using a standardised protocol involving a midvastus approach. Intramedullary femoral and extramedullary tibial alignment guides were used for the neutral mechanical alignment of the knee and soft-tissue releases were performed as necessary. The femoral component was placed with $3^{\circ}$ of external rotation relative to the posterior condyles which was confirmed against the epicondylar and anteroposterior axes in every patient. The intention was to set the proximal tibial osteotomy without any posterior slope. The tibial component was fully cemented using the cement in a doughy state and pressurising it digitally into the proximal tibia. For femoral fixation, cement was placed on the cut surface of the bones and only on the inside of the posterior condyles of the component before it was impacted on to the prepared femur. Postoperatively, quadriceps-strengthening exercises and continuous passive movement were started immediately, and mobilisation increased as tolerated from the first post-operative day. Weight-bearing high-flexion activities such as squatting were also allowed as tolerated. Follow-up visits were scheduled at six weeks, three months, six months, and every six months, thereafter. The range of movement of the knee was measured by the physician assistant nurse with a geniometer at each follow-up, complications were recorded and the Hospital for Special Surgery (HSS) ${ }^{13}$ score obtained. Maximum active flexion was determined from lateral radiographs of the knee obtained with the patient supine. In addition, patients were asked to squat, kneel or sit cross-legged and to prolong the high flexion position at follow-up. Patients were asked by the physician assistant nurse with a questionnaire whether their work involved kneeling or squatting and whether they slept on a raised bed or on the floor. Anteroposterior (AP), lateral and Merchant's view radiographs were obtained at follow-up, and these were analysed using the Knee Society radiological scoring system to delineate radiolucencies around components. ${ }^{14}$ In addition, the posterior femoral condylar offset was evaluated.

Statistical analysis. Data were analysed using the independent $t$-test, the chi-squared test and by logistical regression. Statistical significance was set at $\mathrm{p} \leq 0.05$.

\section{Results}

The mean HSS pain and function scores improved from 5.5 (0 to 10 ) to 14.6 (4 to 18 ) pre-operatively to 28.5 (20 to 30 ) and 20.1 (14 to 22 ) post-operatively, respectively. The mean range of movement increased from $121^{\circ}\left(80^{\circ}\right.$ to $\left.145^{\circ}\right)$ to $132^{\circ}\left(84^{\circ}\right.$ to $\left.150^{\circ}\right)$. The mean pre-operative varus deformity of $9^{\circ}\left(5^{\circ}\right.$ to $\left.30^{\circ}\right)$ corrected to a mean valgus alignment of $3^{\circ}\left(2^{\circ}\right.$ to $\left.7^{\circ}\right)$ post-operatively. However, at a mean of 32 months (30 to 48 ) after operation, progressive complete radiolucent lines were found around the femoral components on the radiographs of 27 (38\%) TKRs. Of these, $15(21 \%)$ which were painful were revised at a mean 23 months (11 to 45 ) after operation.

In order to identify causes of this dramatic rate of loosening, we compared the clinical and radiological data of TKRs which had loosened with those that remained wellfixed. The mean age of the loosened and well-fixed groups at operation was 67.5 years (45 to 79 ) and 69.0 years (53 to 79) and their mean BMI was $25.8 \mathrm{~kg} / \mathrm{m}^{2}$ (19.4 to 32.0$)$ and $26.4 \mathrm{~kg} / \mathrm{m}^{2}$ (20.4 to 30.2 ), respectively, neither of which was statistically significant (independent $t$-test, $\mathrm{p}=0.718$ and $\mathrm{p}=0.485$, respectively). The mean pre-operative active maximum flexion was $134^{\circ}\left(110^{\circ}\right.$ to $\left.148^{\circ}\right)$ in the loosened group and $126^{\circ}\left(84^{\circ}\right.$ to $\left.150^{\circ}\right)$ in the well-fixed group (independent $t$-test, $\mathrm{p}=0.052$ ) and the mean pre-operative range of movement was $128^{\circ}\left(110^{\circ}\right.$ to $\left.145^{\circ}\right)$ in the loosened group and $115^{\circ}\left(80^{\circ}\right.$ to $\left.140^{\circ}\right)$ in the well-fixed group (independent $t$-test, $\mathrm{p}=0.042)$. Before revision surgery or at the final follow-up, the mean maximum flexion was $136^{\circ}\left(110^{\circ}\right.$ to $\left.140^{\circ}\right)$ in the loosened group and $125^{\circ}\left(95^{\circ}\right.$ to $\left.140^{\circ}\right)$ in the well-fixed group (independent $t$-test, $\mathrm{p}=0.022$ ). The percentages of patients whose knees allowed squatting, kneeling, and sitting cross-legged post-operatively was significantly greater in the loosened group $(85 \%, 23$ of 27 knees) than in the well-fixed group (49\%, 22 of 45 knees; chi-squared test, $\mathrm{p}=0.001$ ). Only $26 \%$ (seven knees) and $20 \%$ (nine knees), respectively, of patients in the two groups were capable of prolonged high-flexion activities (chi-squared test, $\mathrm{p}=0.64$ ). More patients in the loosened group worked in a stooped position or slept on the floor than in the well-fixed group. All knees in both groups had a good or excellent function at six months after TKR. (HSS scores: 85 (72 to 96) vs 87 (74 to 98); independent $t$-test, $\mathrm{p}=0.33)$.

During follow-up, there were no wound problems, infection or instability in either group.

When loosening occurred, it was isolated to the femoral component and was not associated with osteolysis. No knee showed loosening or osteolysis associated with the 


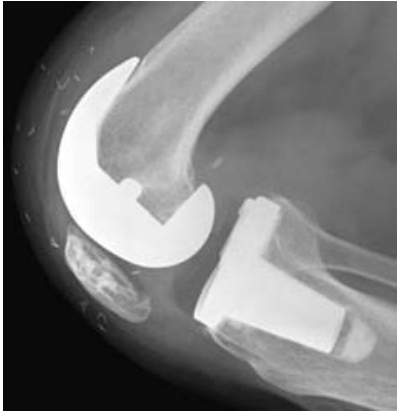

Fig. 1a
Fig. 1b

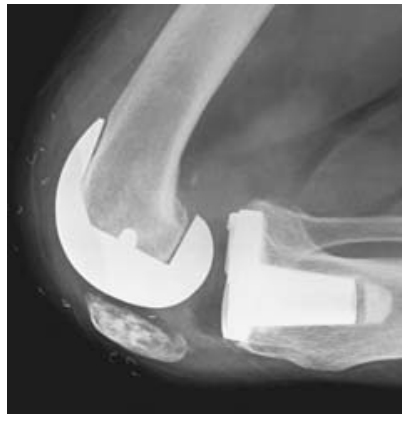

Lateral radiographs of a knee taken a) during the early post-operative period and b) before revision. The femoral component is grossly loose and in a more flexed position. Lucency beneath the anterior flange indicates loosening at the cement-metal interface.

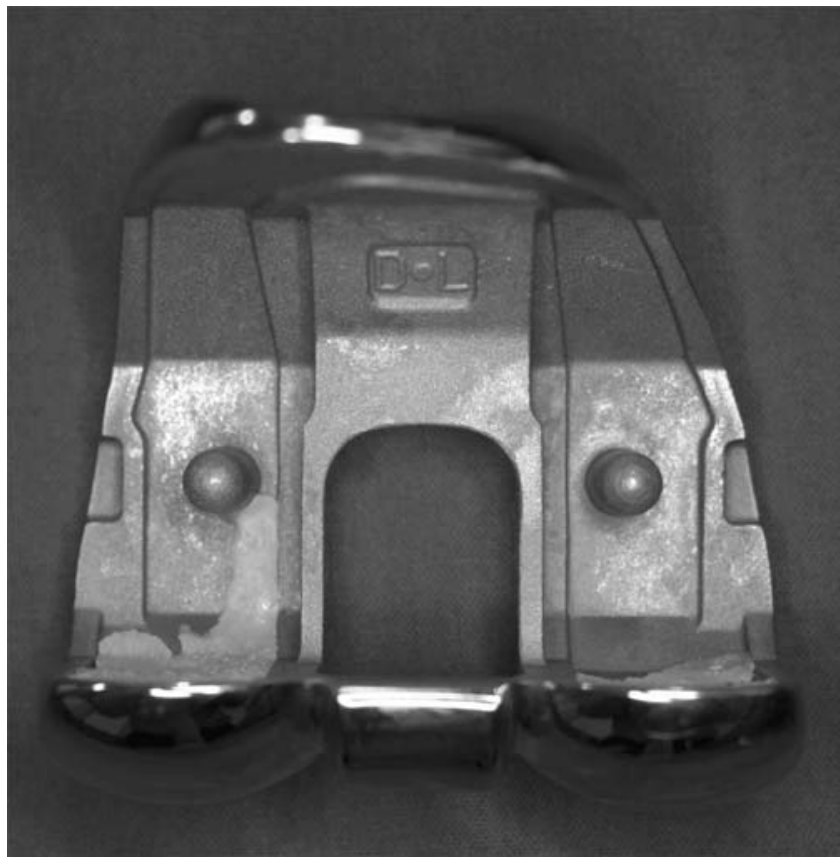

Fig. 2

Photograph of a retrieved femoral component. Cement is attached only to the posterior condyles.

patellar and tibial component. The loosened femoral components migrated into a position of increased flexion from a mean of $4^{\circ}\left(0^{\circ}\right.$ to $\left.10^{\circ}\right)$ immediately post-operatively to a mean of $7^{\circ}\left(1^{\circ}\right.$ to $\left.18^{\circ}\right)$ of flexion of the femoral component ( $\gamma$ angle) at the final review, whereas no migration into flexion was observed in the well-fixed group (independent $t$-test, $p=0.042$ ). Radiolucent lines were observed beneath the anterior flanges of the femoral components on the lateral radiographs (Fig. 1). Although individual changes in the slope of the tibial component and immediate post-operative posterior femoral condylar offset were observed, there were no statistically significant differences in the two groups (independent $t$-test, $\mathrm{p}=0.116$ and 0.098 respectively). During follow-up, posterior femoral condylar offset decreased similarly in both groups (loosened group: 26.3 $\mathrm{mm}$ (21 to 32 ) to $25.8 \mathrm{~mm}$ (20 to 31 ); well-fixed group: $27.3 \mathrm{~mm}$ (21 to 39$)$ to $25.8 \mathrm{~mm}$ (20 to 34$)$; independent $t$-test, $\mathrm{p}=0.777)$.

All 15 loose femoral components were easily removed by hand from their cement mantles, indicating loosening at the cement-metal interface (Fig. 2). The posts and posterior lips of the 15 retrieved polyethylene inserts were preserved and showed no burnishing or delamination. However, the superior articulating polyethylene surfaces had pitting and delamination, and the inferior surfaces (back sides) were marked by rotational scratches and burnishing marks. A similar pattern of scratching and burnishing was observed on the superior surfaces of the titanium-alloy tibial base plates, which were well-fixed.

\section{Discussion}

In vivo analyses of high-flexion designs of TKR have shown that implantation with these prostheses gives kinematic patterns which are similar to those of healthy knees, with excellent early results. ${ }^{10,15-22}$ However, the effects of highflexion designs on maximum flexion have varied, and no studies have shown that the patients adapted themselves to daily activities which involved squatting. ${ }^{23,24}$ Our patients did engage in activities requiring high degrees of flexion, but encountered an unacceptably high rate of loosening of the femoral component with failure at the implant-cement interface.

The Bisurface (Kyocera, Kyoto, Japan) TKR was designed to improve knee flexion after TKR without adversely affecting long-term durability, and has been reported as providing a mean range of flexion of $124^{\circ} .^{25}$ However, the reported rate of loosening was $20 \%$ and $2 \%$, of patients required revision for instability. ${ }^{25}$ Loosening with migration into flexion has been reported in condylartype TKRs, and was considered to be a result of inadequate support of the posterior condyle of the prosthesis. ${ }^{26}$ Several authors have expressed concern that relatively small gains in maximum knee flexion achieved by making changes in the design may substantially reduce the stability of the prosthesis and increase the stresses on the component. ${ }^{11,27}$ Furthermore, these studies demonstrate that the range of flexion acquired after TKR was related more to patient factors than to the design of the implant or surgical technique. ${ }^{12,16,28-30}$ A poor correlation between post-operative maximum flexion and outcome has been reported. ${ }^{31}$ The design changes such as the shortened posterior radius might lead to instability in flexion of the knee. Therefore, we attempted to set the posterior slope at $0^{\circ}$ and took care for the slope not to be reversed.

These concerns about high-flexion activities after TKR have been supported by numerous biomechanical and clinical studies. In the intact knee, high-flexion activities, such as prolonged squatting or kneeling, are strong risk factors 
for tibiofemoral osteoarthritis, and increase peak tibiofemoral stresses to five to seven times body-weight. ${ }^{32-36} \mathrm{At}$ $133^{\circ}$ of flexion, the femur makes contact with the tibia at the posterior edge of the tibial plateau, and the lateral femoral condyle may be regarded as being posteriorly subluxed at full flexion. ${ }^{37-39}$ However, TKR may not restore the characteristic tibiofemoral contact observed in intact knees. After TKR, both medial and lateral contact points have been shown to move posteriorly, but to stop before reaching the posterior edge of the articular surface of the polyethylene tibial insert. ${ }^{40}$ It seems that the current design of the components does not allow the femoral condyle to roll off the polyethylene edge at high degrees of flexion because of the geometry at the posterior lip. ${ }^{40}$ If deep knee flexion is achieved, asymmetrical loading between the medial and lateral compartments of components of a TKR may contribute to loosening and failure of the implant. ${ }^{24}$ In a comparative study of high-flexion implants, contact areas and contact stresses at the post-cam mechanism of a posteriorstabilised TKR were measured when a posterior force of $500 \mathrm{~N}$ was applied to Kirschner Performance (Kirschner medical Corporation, Timonium, Maryland), Scorpio Superflex (Stryker, Allendale, New Jersey), NexGen LPSflex fixed, and NexGen LPS-flex Mobile knee systems (Zimmer). The peak contact stresses of the NexGen LPSflex fixed system at $90^{\circ}, 120^{\circ}$ and $150^{\circ}$ were higher than those of the other implants. ${ }^{39}$ In terms of the geometry of polyethylene inserts, a more relaxed design resulted in less posterior constraint and potentially facilitated femoral rollback, which helped the posterior tibial plateau to clear the posterior femur at deep angles of knee flexion. ${ }^{15,41}$ The mobile-bearing design may solve this problem and provide deep knee flexion. In a previous study, in vivo testing of mobile-bearing displacement under static loading conditions demonstrated that the meniscal movement adapted itself to different weight-bearing conditions and improved fixation at the prosthesis-bone interface. ${ }^{42}$ Mean peak contact stresses on a fixed inlay were found to be greater than those on a mobile inlay, ${ }^{43}$ but other reports have not confirmed these findings. ${ }^{5,44}$ For both mobile and fixed-type implants, the magnitudes and directions of rotation of the components were similar, and the numbers of implants with continuous migration were almost identical. Moreover, mobile-bearing implants displayed more subsidence and fixed-bearing knees showed more lift-off. ${ }^{45}$

In our study, loosening at the cement-metal interface was observed in the 15 revised TKRs. At the hip, the metalcement bone appears to be strongest when the cement is applied to the implant in a low-viscosity state soon after mixing. ${ }^{46}$ While the optimal surface finish of cemented femoral components remains controversial, mechanical interactions resulting from surface roughness are important. ${ }^{47-50}$ Roughened polymethylmethacrylate pre-coated surfaces on the femoral component of a hip replacement were found to have significantly greater tensile and shear strengths than polished surfaces. ${ }^{46}$ However, the loosening of roughened components is associated with the generation of excessive wear debris and may precipitate osteolysis. ${ }^{51,52}$

As the knee flexes beyond $135^{\circ}$, the patella clears the femoral groove and is in contact only with the condyles. Therefore, during deep knee flexion, the distally directed force on the femoral component is resisted not by the bony patella but by the quadriceps muscle, which is elastic and weak in elderly, arthritic patients. ${ }^{53}$ Femoral components with intramedullary stems may be appropriate for high-risk patients, ${ }^{26}$ but this may in turn produce greater stress shielding and secondary weakening on the bone. ${ }^{54}$

Our study has some inherent weaknesses because of its retrospective, non-comparative design and the relatively small number of patients. Many of the enrolled patients followed a traditional Korean life style, which involved working and sleeping on floors and demanded weight-bearing high-flexion activities in daily life. Nevertheless, we have not previously experienced such a high rate of early loosening for any design of TKR. Accordingly, a prospective, randomised study is required to determine whether the increased loading in the knee during deep flexion substantially increases wear of the insert or loosening of the components.

The authors wish to thank the medical research collaborating centre at Seoul National University for assistance with the statistical analyses. The authors thank Ji Sun Shin for her contribution to this study and the medical research collaborating center at Seoul National University for assistance with statistical analysis.

No benefits in any form have been received or will be received from a commercial party related directly or indirectly to the subject of this article.

\section{References}

1. Cross MJ, Parish EN. A hydroxyapatite-coated total knee replacement: prospective analysis of 1000 patients. J Bone Joint Surg [Br]2005;87-B:1073-6.

2. Epinette JA, Manley MT. Hydroxyapatite-coated total knee replacement: clinical experience at 10 to 15 years. J Bone Joint Surg [Br] 2007;89-B:34-8.

3. Oliver MC, Keast-Butler OD, Hinves BL, Sheppard JA. A hydroxyapatite-coated Insall-Burstein II total knee replacement: 11 year results. J Bone Joint Surg [Br] 2005;87-B:478-82

4. Banks S, Bellemans J, Nozaki $\mathbf{H}$, et al. Knee motions during maximum flexion in fixed and mobile-bearing arthroplasties. Clin Orthop 2003:410:131-8.

5. Kurosaka M, Yoshiya S, Mizuno K, Yamamoto T. Maximizing flexion after total knee arthroplasty: the need and the pitfalls. J Arthroplasty 2001;17(Suppl 1):59-62.

6. Mulholland SJ, Wyss UP. Activities of daily living in non-Western cultures: range of motion requirements for hip and knee joint implants. Int $J$ Rehabil Res 2001;24:191-8.

7. Hefzy MS, Kelly BP, Cooke TD, al-Baddah AM, Harrison L. Knee kinematics in vivo of kneeling in deep flexion examined by bi-planar radiographs. Biomed Sci Instrum 1997;33:453-8.

8. Bellemans J, Banks S, Victor J, Vandenneucker H, Moemans A. Fluoroscopic analysis of the kinematics of deep flexion in total knee arthroplasty: influence of posterior condylar offset. J Bone Joint Surg [Br] 2002;84-B:50-3.

9. Sultan PG, Most E, Schule S, Li G, Ribash HE. Optimizing flexion after total knee arthroplasty: advances in prosthetic design. Clin Orthop 2003;16:167-73.

10. Argenson JN, Scuderi GR, Komistek RD, et al. In vivo kinematic evaluation and design considerations related to high flexion in total knee arthroplasty. J Biomech 2005;38:277-84

11. Ranawat CS. Design may be counterproductive for optimising flexion after TKR. Clin Orthop 1985;194:285-90.

12. Delp SL, Kocmond JH, Sterm SH. Tradeoffs between motion and stability in posterior substituting knee arthroplasty design. J Biomech 1995;28:1155-66.

13. Li PL, Zamora J, Bentley G. The results at ten years of the Insall-Burstein II total knee replacement: clinical, radiological and survivorship studies. J Bone Joint Surg [Br] 1999;81-B:647-53. 
14. Ewald FC. The Knee Society total knee arthroplasty roentgenographic evaluation and scoring system. Clin Orthop 1989;248:9-12.

15. Klein GR, Parvizi J, Rapuri VR, Austin MS, Hozack WJ. The effect of tibial polyethylene insert design on range of motion: evaluation of in vivo knee kinematics by a computerized navigation system during total knee arthroplasty. J Arthroplasty 2004;19:986-91.

16. Bin SI, Nam TS. Early results of high-flex total knee arthroplasty: comparison study at 1 year after surgery. Knee Surg Sports Traumatol Arthrosc 2007;15:350-5.

17. Huang HT, Su JY, Wang GJ. The early results of high-flex total knee arthroplasty: a minimum of 2 years of follow-up. J Arthroplasty 2005;20:674-9.

18. Kim YH, Sohn KS, Kim JS. Range of motion of standard and high-flexion posterior stabilized total knee prostheses: a prospective, randomized study. J Bone Joint Surg [Am] 2005;87-A:1470-5

19. Argenson JN, Komistek RD, Mahfouz M, et al. A high flexion total knee arthroplasty design replicates healthy knee motion. Clin Orthop 2004;428:174-9.

20. Coughlin KM, Incavo SJ, Doohen RR, et al. Kneeling kinematics after total knee arthroplasty: anterior-posterior contact position of a standard and a high-flex tibial insert design. J Arthroplasty 2007;22:160-5

21. Li G, Most E, Sultan PG, et al. Knee kinematics with a high-flexion posterior stabilized total knee prosthesis: an in vitro robotic experimental investigation. J Bone Joint Surg [Am]2004;86-A:1721-9.

22. Morra EA, Greenwald AS. Polymer insert stress in total knee designs during high-flexion activities: a finite element study. J Bone Joint Surg [Am]2005;87-A(Suppl 2):120-4.

23. Seon JK, Song EK, Lee JY. Comparison of range of motion of high-flexion prosthesis and mobile-bearing prosthesis in total knee arthroplasty. Orthopedics 2005;28(10 Suppl):1247-

24. Most E, Sultan PG, Park SE, Papannagari R, Li G. Tibiofemoral contact behavior is improved in high-flexion cruciate retaining TKA. Clin Orthop 2006;452:59-64.

25. Akagi M, Nakamura T, Matsusue $\mathbf{Y}$, et al. The Bisurface total knee replacement: a unique design for flexion: four-to-nine-year follow-up study. J Bone Joint Surg [Am] 2000;82-A:1626-33.

26. King TV, Scott RD. Femoral component loosening in total knee arthroplasty. Clin Orthop 1985;194:285-90.

27. Ritter MA. High-flexion knee designs: more hype than hope?: in the affirmative. J Arthroplasty 2006;21(Suppl 1):40-1.

28. Nagura T, Dyrby C0, Alexander EJ, Andriacchi TP. Mechanical loads at the knee joint during deep flexion. J Orthop Res 2002;20:881-6.

29. Bellemans J, Robijns F, Duerinckx J, Banks S, Vandenneucker H. The influence of tibial slope on maximal flexion after total knee arthroplasty. Knee Surg Sports Traumatol Arthrosc 2005;13:193-6.

30. Most E, Li F, Sultan PG, Park SE, Rubash HE. Kinematic analysis of conventional and high-flexion cruciate-retaining total knee arthroplasties: an in vitro investigation. J Arthroplasty 2005;20:529-35.

31. Park KK, Chang CB, Kang YG, Seong SC, Kim TK. Correlation of maximum flexion with clinical outcome after total knee replacement in Asian patients. J Bone Joint Surg [Br] 2007;89-B:604-8.

32. Thambyah A, Goh JC, De SD. Contact stresses in the knee joint in deep flexion. Med Eng Phys 2005;27:329-35.

33. Zhang Y, Hunter DJ, Nevitt MC, et al. Association of squatting with increased prevalence of radiographic tibiofemoral knee osteoarthritis: the Beijing Osteoarthritis study. Arthritis Rheum 2004;50:1187-92.

34. Felson DT, Hannan MT, Naimark A, et al. Occupational physical demands, knee bending and knee osteoarthritis: results from the Framingham Study. J Rheumatol 1991:18:1587-92.
35. Coggon D, Croft P, Kellingray S, et al. Occupational physical activities and osteoarthritis of the knee. Arthritis Rheum 2000;43:1443-9.

36. Nagura T, Matsumoto H, Kiriyama Y, Chaudhari A, Andriacchi TP. Tibiofemoral joint contact force in deep knee flexion and its consideration in knee osteoarthritis and joint replacement. J App/ Biomech 2006;22:305-13.

37. Li G, Zayontz S, DeFrate LE, et al. Kinematics of the knee at high flexion angles: an in vitro investigation. J Orthop Res 2004;22:90-5.

38. Nakagawa S, Kadoya Y, Todo S, et al. Tibiofemoral movement 3: full flexion in the living knee studied by MRI. J Bone Joint Surg [Br] 2000;82-B:1199-200.

39. Nakayama K, Matsuda S, Miura H, et al. Contact stress at the post-cam mechanism in posterior-stabilised total knee arthroplasty. J Bone Joint Surg [Br] 2005;87B:483-8

40. Li G, Suggs J, Hanson G, et al. Three-dimensional tibiofemoral articular contact kinematics of a cruciate-retaining total knee arthroplasty. J Bone Joint Surg [Am] 2006;88-A:395-402.

41. Klein GR, Restrepo C, Hozack WJ. The effect of knee component design changes on range of motion evaluation in vivo by a computerized navigation system. J Arthroplasty 2006;21:623-7.

42. Russo A, Montagna L, Bragonzoni L, Zampagni ML, Marcacci M. Fixation of total knee arthroplasty improved by mobile-bearing design. Clin Orthop 2005;437:186-95

43. Stukenborg-Colsman C, Ostermeier S, Hurschler C, Wirth CJ. Tibiofemoral contact stress after total knee arthroplasty: comparison of fixed and mobile-bearing inlay designs. Acta Orthop Scand 2002;73:638-46.

44. Chapman-Sheath PJ, Bruce WJ, Chung WK, et al. In vitro assessment of proximal polyethylene contact surface areas and stresses in mobile bearing knees. Med Eng Phys 2003:25:437-43.

45. Henricson A, Dalen T, Nilsson KG. Mobile bearings do not improve fixation in cemented total knee arthroplasty. Clin Orthop 2006;448:114-21.

46. Shepard MF, Kabo JM, Lieberman JR. Influence of cement technique on the interface strength of femoral components. Clin Orthop 2000;381:26-35.

47. Nuno N, Amabili M, Groppetti R, Rossi A. Static coefficient of friction between Ti6A1-4V and PMMA for cemented hip and knee implants. J Biomed Mater Res 2002:59:191-200

48. Nuno N, Groppetti R, Senin N. Static coefficient of friction between stainless steel and PMMA used in cemented hip and knee implants. Clin Biomech (Bristol, Avon) 2006;21:965-62.

49. Crowninshield RD, Jennings JD, Laurent ML, Maloney WJ. Cemented femoral component surface finish mechanics. Clin Orthop 1998;355:90-102.

50. Pittman GT, Peters CL, Hines JL, Bachus KN. Mechanical bone strength of the cement-tibial component interface in total knee arthroplasty. J Arthroplasty 2006:21:883-8.

51. Cheng K, Pruitt L, Zaloudek C, Ries MD. Osteolysis caused by tibial component debonding in total knee arthroplasty. Clin Orthop 2006;443:333-6.

52. Barink M, Verdonschot N, de Waal Malefijt M. A different fixation of the femoral component in total knee arthroplasty may lead to preservation of femoral bone stock. Proc Inst Mech Eng [H]2003;217:325-32.

53. Hefzy MS, Kelly BP, Cooke TD. Kinematics of the knee joint in deep flexion: a radiographic assessment. Med Eng Phys 1998;20:302-7.

54. van Lenthe GH, Willems MM, Verdonschot N, de Waal Malefijt MC, Huiskes R. Stemmed femoral knee prostheses: effects of prosthetic design and fixation on bone loss. Acta Orthop Scand 2002;73:630-7. 